\title{
Force Degradation of Elastomeric Chains after Storage Time and Mechanical Brushing
}

\author{
Antonio Carlos da Silva Chaves-Filho $0^{1}$, Ana Rosa Costa ${ }^{1,2}$ \\ Lincoln Pires Sousa Borges $0^{2}$, Eduardo Cesar Almada Santos $0^{3}$, \\ Marcus Vinicius Crepaldi@ ${ }^{4}$, Silvia Amélia Scudeler Vedovello@1, \\ Américo Bortolazzo Correr@2 ${ }^{2}$, Lourenço Correr-Sobrinho ${ }^{2}$.
}

\begin{abstract}
The purpose of this in vitro study was to evaluate the force decrease of different elastomeric chains after different times: initial, 10 minutes, 1 day, 28 days and after mechanical brushing. Twenty orthodontic elastomeric chains segments were utilized for each commercial brand. Initially, the elastomeric chain of $15 \mathrm{~mm}$ long were immediate stretched up to $20 \mathrm{~mm}$ in an Instron and the force was measured in gf. After all specimens were placed stretched on rectangular acrylic jigs with distance of $20 \mathrm{~mm}$, immersed in deionized water at $37^{\circ} \mathrm{C}$ for 10 minutes and the force (gf) was measured again. Five test measurements of remaining force were made at the following time intervals: initial, 10 minutes, 1 day, 28 days and mechanical brushing. After 28 days, the acrylic plates with the specimens were adapted in the mechanical brushing machines (MSCT 3) and the elastomeric chains were submitted to mechanical brushing and the force (gf) measure again. The force (gf) was submitted to mixed-model ANOVA and Sidak post-hoc test $(\alpha=0.05)$. A statistically significant reduction in the force was found for all orthodontic elastomeric chain types after 1 day, 28 days and mechanical brushing $(\mathrm{p}<0.05)$. Morelli and $3 \mathrm{M}$ Unitek elastomeric chains showed significantly higher force than Abzil and GAC $(\mathrm{p}<0.05)$ after 1 day, 28 days and mechanical brushing. In conclusion, the force delivered by all elastomeric chains decayed rapidly over time. Morelli and 3M Unitek elastomeric chains consistently had a significantly greater force after mechanic brushing, while GAC the lowest.
\end{abstract}

\section{Introduction}

The elastomeric chains are used extensively in orthodontics for intra-arch teeth movement. They are practical, low cost, and comfortable for patients, effective in diastemas closing, correcting rotations, shifting the midline, achieving general space closure and removal requires little chair time for the dentist $(1,2)$. Their using is larger, due to these factors and high degree of professional acceptance.

However, the elastomeric chains deteriorate rapidly in the oral environment and do not produced continuous force for teeth movement for a long period of time. The reduction of force occurs at 1 day, showing loss of $15.8 \%$ to $59.5 \%$ of the initial force. Afterwards, changes occur with decline in the force decay of elastomeric chains having $9.05 \%$ to $74.4 \%$ of their original force until four weeks (2-12). A rapid loss of force in an elastomeric chain causes inefficient tooth movement, which will result in an increased number of consultations for reactivate the appliance (12). Previous studies showed that the force degradation of different orthodontic elastics may be influenced by many factors, such as time, mastication, pre-stretch, exposure to heat, color (12), temperatures (13), saliva (7), different $\mathrm{pH}(14)$, and alcohol concentrations in mouthwashes $(2,9)$.

For the other hand, beyond of mouthwashes the using of mechanical brushing during orthodontics treatment is largely recommended with goal for the maintenance of oral hygiene, reduction in the frequency of caries lesions (15), and dental biofilm (16). Nevertheless, little is known about the mechanical brushing effect on the force degradation of elastomeric chains.

Therefore, the aim of this in vitro study was to evaluate the force decrease of five elastomeric chains brands evaluated initial, 10 minutes, 1 day, and 28 days and submitted to simulated mechanical brushing. Two hypotheses were tested: 1) The storages periods and mechanical brushing will not affect the force decrease of all elastomeric chains brands; 2) No significant difference in force will be observed among all elastomeric chain brands. 


\section{Material and Methods}

Orthodontic elastomeric chains (Dentsply GAC; Tokyo, Japan, 3M Unitek; Monrovia, CA, USA, G \& H Orthodontics; Franklin, IN, USA, Abzil; 3M do Brazil, Sao Jose do Rio Preto, SP, Brazil; and, Morelli; Sorocaba, SP, Brazil) with medium conformation, gray color and within the expiry date were used.

The elastomeric chains are manufactured in a single continuous chain, they were cut to a standard length. The orthodontic elastomeric chains (GAC; G \& H Orthodontics; Abzil and Morelli) were cut into $15 \mathrm{~mm}$ long segments (five links). The 3M Unitek was cut into $15 \mathrm{~mm}$ long segments (six links) because the links are smaller than the links of other elastomeric chains. Twenty orthodontic elastomeric chains segments were utilizing for each commercial brands, totalized 100 segments.

Initially, the orthodontic elastomeric chain segments were measured using a digital caliper (Mitutoyo Corporation, Tokyo, Japan) and submitted to distention of 50\% of the original length. Afterwards, the orthodontic elastomeric chains segments were placed in a universal mechanical testing machine (Model 4411; Instron, Canton, USA) and submitted to distention in $20 \mathrm{~mm}$ at a crosshead speed of $5.0 \mathrm{~mm} /$ minute $(2,17)$ and the force was measured in $\mathrm{gf}$.

Afterwards, all samples were placed stretched on rectangular acrylic jigs (Acrilinjet, São Paulo, SP, Brazil). One hundred rectangular acrylic jigs (60 mm long x $30 \mathrm{~mm}$ wide x $3 \mathrm{~mm}$ thick) were fabricated. One mark was made in each side, placed equidistantly $20 \mathrm{~mm}$ between them. The acrylic jigs were perforated on the mark with spherical diamond bur (KG Sorensen, Barueri, Brazil). The stainless steels pins $(0.9 \mathrm{~mm}$ diameter x $10 \mathrm{~mm}$ height $)$ were symmetrically aligned in rows and adapted in each orifice with acrylic resin (VIPI, Pirassununga, SP, Brazil). The two most lateral stainless steels pins were spaced $20 \mathrm{~mm}$ from each other (2). The acrylic jigs allowed the orthodontic elastomeric chains segments stretched to be completely immersed in deionized water at $37^{\circ} \mathrm{C}$ for 10 minutes and the force (gf) was measured again in a universal testing machine (Instron) as previously described. Five test measurements of remaining force were made at the following time intervals: initial, 10 minutes, 1 day, 28 days and mechanical brushing.

Afterwards the 28 days measurements, the acrylic jigs with specimens were submitted to a simulated mechanical brushing technique using a mechanical device (MSCT 3; Marnucci, Sao Carlos, SP, Brazil) in which every specimen was individually brushed. The mechanical brushing procedure was carried out with soft nylon bristles (Oral B - Classic; Protector, Rio de Janeiro, RJ, Brazil) fixed to the device with cyanoacrylate glue (Zapit; Dental Ventures, Corona, USA). Care was taken to ensure that the bristles were perpendicular to the surface of each specimen and touched the surface evenly. A slurry of toothpaste (Colgate Total 12 Clean Mint; Colgate-Palmolive, Sao Bernardo do Campo, SP, Brazil) and deionized water in a 50:50 (w/w) was used. The volume of slurry needed to maintain a constant supply of abrasive between brush and the specimen surfaces were provided by 37.5 grams of dentifrice and deionized water ( 75 grams total). The specimens were brushed for 840 times at $1.5 \mathrm{~Hz}$ using a brush head force of 350 grams (18). After the simulated brushing procedure, the specimens were rinsed with air/water spray for $30 \mathrm{~s}$ and stored in $100 \%$ humidity until force (gf) values were obtained using the testing machine (Instron). The force (gf) was submitted to mixed-model ANOVA and Sidak post hoc test $(\alpha=0.05)$.

\section{Results}

The force mean values are shown in Table 1. Significant differences between the orthodontic elastomeric chains $(\mathrm{p}<0.00001)$ and time $(\mathrm{p}<0.00001)$ were detected. The interaction between orthodontic elastomeric chains and time $(\mathrm{p}<0.00001)$ factors were significant. 
Table 1. Mean force values (gf) and standard deviation for orthodontic elastomeric chains after the time intervals and mechanical brushing.

\begin{tabular}{cccccc} 
Orthodontic & \multicolumn{3}{c}{ Period } \\
\cline { 2 - 6 } $\begin{array}{c}\text { Elastomeric } \\
\text { Chain }\end{array}$ & Initial & $\mathbf{1 0}$ minutes & $\mathbf{1}$ day & 28 days & $\begin{array}{c}\text { Mechanical } \\
\text { brushing }\end{array}$ \\
\hline Morelli & $265.0 \pm 10.6 \mathrm{aA}$ & $264.8 \pm 12.2 \mathrm{aA}$ & $164.2 \pm 7.8 \mathrm{aB}$ & $140.2 \pm 6.1 \mathrm{aC}$ & $109.7 \pm 6.2 \mathrm{aD}$ \\
3 M Unitek & $263.1 \pm 10 \mathrm{aA}$ & $263.0 \pm 9.2 \mathrm{aA}$ & $162.4 \pm 7.8 \mathrm{aB}$ & $139.5 \pm 4.3 \mathrm{aC}$ & $110.1 \pm 6.7 \mathrm{aD}$ \\
G \& H & $260.2 \pm 10.1 \mathrm{aA}$ & $259.9 \pm 8 \mathrm{aA}$ & $145.8 \pm 5.8 \mathrm{bB}$ & $120.5 \pm 6 \mathrm{bC}$ & $94.1 \pm 4.9 \mathrm{bD}$ \\
Abzil & $247.5 \pm 7.5 \mathrm{bA}$ & $247.4 \pm 4.8 \mathrm{bA}$ & $146.1 \pm 5.9 \mathrm{bB}$ & $121.3 \pm 4.9 \mathrm{bC}$ & $95.3 \pm 5.3 \mathrm{bD}$ \\
GAC & $206.1 \pm 11 \mathrm{cA}$ & $205.9 \pm 9 \mathrm{cA}$ & $130.2 \pm 5.9 \mathrm{cB}$ & $114.2 \pm 6.6 \mathrm{cC}$ & $83.1 \pm 5.3 \mathrm{cD}$ \\
\hline
\end{tabular}

Means followed by different capital letters in the same row and small letters in the column are significantly different at $\mathrm{p}<0.05$ (Sidak post hoc test).

When the groups were evaluated individually over time (Table 1 and Figure 1), a statistically significant reduction in the force was found for all orthodontic elastomeric chain types after 1 day, 28 days and mechanical brushing in relation to initial and 10 minutes condition $(\mathrm{p}<0.05)$. The force after 1 day was significantly higher than 28 days and after mechanical brushing for all orthodontic elastomeric chain $(\mathrm{p}<0.05)$. The lowest values of strength were obtained after mechanical brushing. No statistically difference was observed between initial and after 10 minutes for all orthodontic elastomeric chain ( $p>0.05$ ). In comparation with the materials tested at initial, 10 minutes, 1 day, 28 days and after mechanical brushing led to a reduction of force of $0.10 \%, 38.10 \%, 47.10 \%$ and $58.61 \%$, respectively, for the Morelli, $0.03 \%, 38.27 \%, 46.98 \%$ and $58.16 \%$, respectively, for the 3M Unitek, $0.12 \%, 43.97 \%$, $53.69 \%$ and $63.84 \%$, respectively, for the $\% \mathrm{G} \& \mathrm{H}$ Orthodontics, $0.04 \%, 40.97 \%, 50.99 \%$ and $61.49 \%$, respectively, for the Abzil, and $0.09 \%, 36.83 \%, 44.59 \%$ and $59.68 \%$, respectively, for the GAC.

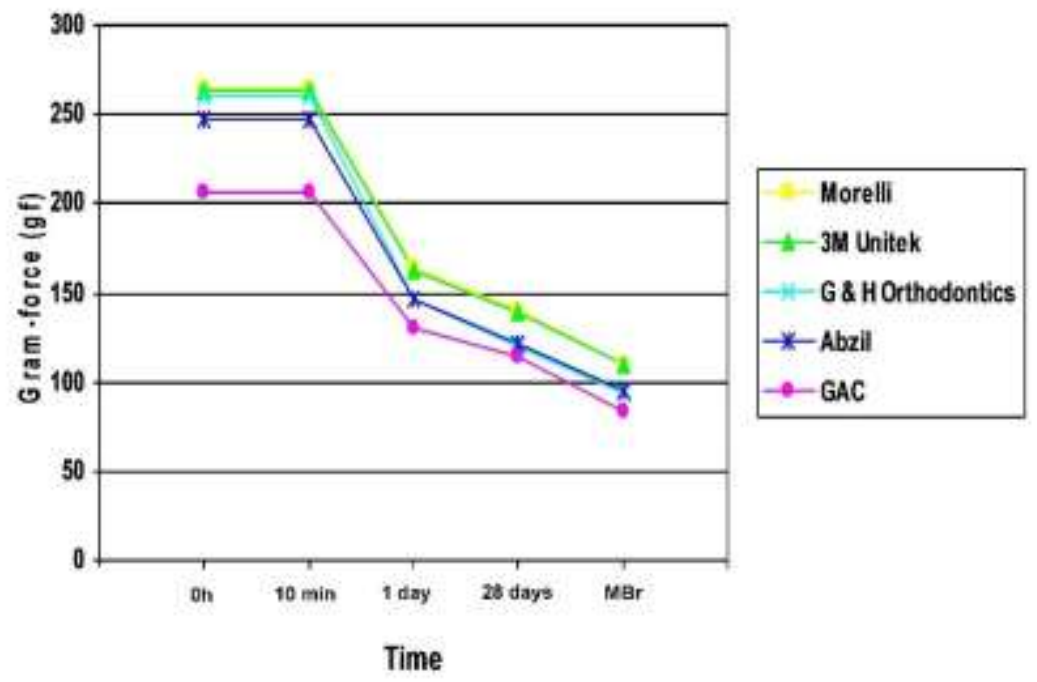

Figure 1. Elastomeric chains Morelli, 3M Unitek, Orthometric, Abzil and GAC behavior in the 28 days period and after mechanical brushing.

With respect to the groups at the same time interval, statistically significant differences were found between Morelli, 3M Unitek and G \& H Orthodontics elastomeric chains in relation to Abzil and GAC $(\mathrm{p}<0.05)$ at the time intervals of initial and 10 minutes (Table 1$)$. No statistically difference was observed among Morelli, 3M Unitek and G \& H Orthodontics ( $p>0.05$ ). For the period of 1 day, 28 days and mechanical brushing, Morelli and $3 \mathrm{M}$ Unitek had significantly higher force than $\mathrm{G} \& \mathrm{H}$ Orthodontics, Abzil and GAC ( $\mathrm{p}<0.05)$. GAC showed the lowest force in all periods evaluated ( $<<0.05)$. No statistically difference was observed between Morelli and 3M Unitek, and G \& H Orthodontics and Abzil ( $\mathrm{p}>0.05)$. 


\section{Discussion}

Elastomeric chains are important and commonly used in orthodontics to facilitate tooth biomechanics mainly due to strength transmission to the teeth. However, these materials are not ideal, because during the activation period of the treatment the force generated diminishes gradually $(6,13)$. Several studies have tried to establish the mechanical and environmental factors, such as humid conditions, exposure to the heat, pre-stretching, incorporation of dyes, and disinfection and sterilization that can contribute to the force degradation of orthodontic elastics $(9,13,14)$.

The methods used in this laboratory study try to simulate an intra-arch use of orthodontic elastomeric chains after immersion with deionized water at a $37^{\circ} \mathrm{C}$ since a basic environment preserves the force of the orthodontic elastomers compared to acidity of solution and high temperature that could potentiality reduce the force $(2,11,19)$. Previous study showed that the water bath testing is a most realistic environment used for large-scale test of orthodontic elastomers than in air (20). However, they may only be adequate for short-term test (20). On the other hand, the dynamic testing estimates distance changes and causes a larger decrease in force early in testing of the elastics (21).

Commonly, the elastomeric chain is evaluated over period of 28 days, because this period is used frequently by orthodontists to exchange synthetic elastics $(2,9,20)$. In this study, the force was measured in the initial, 10 minutes, 1 day, 28 days and mechanical brushing. The mechanical brushing was used to simulate the procedure done daily by patients to brush the teeth. It would be interesting to evaluate how the mechanical brushing can affect orthodontic elastomeric chains after 28 days, period used by orthodontists to exchange elastics. The choice of 840 cycles was not arbitrary because it reflects the time used by the patient to brush the teeth per day for 28 days. Previous study reported that the average person brushes between 25-30 cycles per day on a given tooth surface. This equates to 9,125 to 10,950 cycles per year. Thus, 840 cycles were used in this study to simulate 28 days of brushing (18).

The first hypothesis of this study, which stated that the storages periods and mechanical brushing will not affect the force decrease of all elastomeric chains, was rejected. The results showed a significant decrease in the amount of force generated after 1 day, 28 days and mechanical brushing in relation to the initial period and 10 minutes. The lowest values of strength were obtained after mechanical brushing. The biggest drop of the force unleashed by all orthodontic elastomeric chain occurred in the first hour and after mechanical brushing in relation to the initial period, with a significant difference. When compared to the initial period, the force for elastomeric chain Morelli, 3M Unitek, G \& H Orthodontics, Abzil and GAC decreased by roughly $38.10 \%, 38.27 \%, 43.97 \%, 40.97 \%$ and $36.83 \%$ after storage for 1 day; and, $47.10 \%, 46.98 \%, 53.69 \%, 50.99 \%$ and $44.59 \%$ after 28 days, respectively. However, after mechanical brushing greater reductions in the force of $58.61 \%, 58.16 \%, 63.84 \%, 61.49 \%$ and $59.68 \%$ for Morelli, 3M Unitek, G \& H Orthodontics, Abzil and GAC were observed in relation to the initial period, respectively. The results of the present study are in agreement with those of previous studies, which showed loss of $15.8 \%$ to $59.5 \%$ of the initial force on the first day of use. These values continued to decrease between $35 \%$ to $90.95 \%$, after approximately 4 weeks, with the elastic chains having approximately $9.05 \%$ to $65 \%$ of their original force (2-12). Pithon et al. observed the greatest relaxation and loss of force of the elastomeric chain with $15.8 \%$ to $35.9 \%$ within 24 hours and $25.67 \%$ to $47 \%$ after 28 days (12). Previous studies showed that the greatest loss of force in elastomeric chains occurred after 24 hours of $46 \%$ to $49 \%$ and the force continue to decrease of $64 \%$ to $71.61 \%$ after 28 days (10). Other study showed that elastomeric chains exhibited a high percentage of force loss $42.18 \%$ to $53.38 \%$ during the first 24 hours, but after the force decay continued progressively $66.30 \%$ to $86.48 \%$ until 28 days (5). Another study showed that the force decay over time with $48.2 \%$ after 1 day and $59.7 \%$ after 28 days in relation to initial period in water (9). In this same line, Losito et al. showed that elastomeric chain decreased significantly in the amount of force generated after one day, around 53.9\%. These values continued to decrease, reaching $71.42 \%$ after 28 days (2). The reduced elasticity in association with nearly constant forces suggests that the elastomeric chains begin to become brittle and lose elasticity after a short time (6). The force degradation is significant during orthodontic treatment, and it may depend on the magnitude of the force and the precision desired by the clinician (21). However, it does not exist consensus in the literature about this value but have been used $10 \%$ of difference is a measure that could be clinically significant for elastomeric chains (22). According to Kersey et al. 10\% is probably reasonable number and should be kept in mind when discussing the results above and relating them to the clinical setting, but the force was measured only until 24 hours (21). In this study, after storage for 28 days and mechanical brushing, the reduction was approximately $58 \%$ to $63 \%$. 
In relation to the factor of elastomeric chain, statistically significant differences were found to Morelli, 3M Unitek and G \& H Orthodontics elastomeric chains in relation to Abzil and GAC, initial e after 10 minutes. For the period of 1 day, 28 days and mechanical brushing, Morelli and 3M Unitek had significantly higher force than G \& H Orthodontics, Abzil and GAC. Then, the results indicate that the second hypothesis was not accept. The performance of elastomeric chains Morelli and 3M Unitek after 1 day, 28 days and mechanical brushing were higher than G \& H Orthodontics, Abzil and GAC at all times. GAC showed the lowest force in all periods evaluated. One possible explanation for this difference is that some polymeric chain was less susceptible to water sorption and the absorption of liquids causes alterations in the elastomeric chains (23). Furthermore, the reduced elasticity in association with nearly constant forces during failure suggests that the elastomeric material begins to become brittle and lose elasticity after only a short time (6). In addition, manufacturing process, the composition of elastics, brands of elastomeric chains, variability in diameter and distance between links may have contributed to the force differences between different brands and force decay when in contact with distilled water, saliva and chemicals $(10,21,24)$. Besides, these elastic chains may not respond in the same manner or with same force degradation when compared to other elastic chains brands.

On the other hand, some factors made it difficult to quantify the force needed to promote the dental movements required to close gaps. According to previous study, better clinical results for space closure in orthodontics was with forces ranging between $150 \mathrm{~g}$ to $200 \mathrm{~g} \mathrm{(25).} \mathrm{Thus,} \mathrm{considering} \mathrm{the} \mathrm{force}$ values found in the present study on the first day of activation and at the end of mechanical brushing, the elastics lost their effectiveness to close spaces time. Thus, the results of this study confirm the need to replace the elastomeric chains used in orthodontic treatment every four weeks with mechanical brushing in order to obtain a better performance. The alternative to the elastomeric chain using might be the NiTi spring. The NiTi spring is appropriate for exercising the characteristic of continuous force that produces rapid tooth movement with low loss of force (11).

In summary, the results showed that different intervals of time and the mechanical brushing influenced the force degradation for all elastomeric chains. The force delivered by all elastomeric chains decayed significantly from the first day after activation until after mechanical brushing. Morelli and 3M Unitek elastomeric chains consistently had a significantly greater force after mechanic brushing, while GAC the lowest. Although the study had showed that time and mechanical brushing was significant on the force degradation of elastomeric chains, direct generalization of the results e o impact in clinical situations should be taken with caution. Future studies should be carried out to investigate other time intervals after immersion in water, disinfectant solutions with different $\mathrm{pH}$ associated to mechanical brushing, the influence of the number of rings and size of the elastomeric chains as well as the temperature variation of the environment and the use of NiTi spring.

\section{Acknowledgement}

This study was supported by Conselho Nacional de Desenvolvimento Científico e Tecnológico CNPq (grant 304493/2014-7).

\section{Resumo}

O objetivo deste estudo in vitro foi avaliar a redução da força de diferentes cadeias elastoméricas após diferentes tempos: inicial, 10 minutos, 1 dia, 28 dias e após escovação mecânica. Vinte segmentos de cadeias elastoméricas ortodônticas foram utilizadas para cada marca comercial. Inicialmente, a cadeia elastomérica de $15 \mathrm{~mm}$ de comprimento foi esticada imediatamente até $20 \mathrm{~mm}$ na Instron e a força foi medida em (gf). Após, todas as amostras foram adaptadas esticadas em placas retangulares de acrílico na distância de $20 \mathrm{~mm}$, imersas em água deionizada a $37^{\circ} \mathrm{C}$ por 10 minutos e a força (gf) foi medida novamente. Cinco medidas de força foram feitas nos seguintes intervalos de tempo: inicial, 10 minutos, 1 dia, 28 dias e após a escovação mecânica. Após 28 dias, as placas de acrílico com as amostras foram adaptadas na máquina de escovação (MSCT 3) e as cadeias elastoméricas foram submetidas a escovação mecânica e a medida de força (gf) novamente. Os dados da força (gf) foram submetidos a ANOVA modelo misto e teste post-hoc de Sidak $(\alpha=0,05)$. Uma redução estatisticamente significativa na força foi encontrada para todos os tipos de cadeia elastomérica ortodôntica após 1 dia, 28 dias e escovação mecânica $(p<0,05)$. As cadeias elastoméricas Morelli e 3M Unitek apresentaram força significativamente superior em relação a Abzil e GAC ( $<<0,05)$ após 1 dia, 28 dias e escovação mecânica. Em conclusão, a força distribuída por todas as cadeias elastoméricas decaiu rapidamente com 
o tempo. As cadeias elastoméricas Morelli e 3M Unitek consistentemente tiveram uma força significativamente maior após a escovação mecânica, enquanto GAC a mais baixa.

\section{References}

1 - Wong AK. Orthodontic elastic materials. Angle Orthod. 1976;46:196-205.

2 - Losito KAB, Lucato AS, Tubel CAM, Correa CA, Dos Santos JCB. Force decay in ortodontic elastomeric chains after immersion in disinfection. Braz J Oral Sci 2014;13:266-269.

3 - Baratieri C, Mattos CT, Alves M Jr, Lau TC, Nojima LI, de Souza MM, et al.. In situ evaluation of orthodontic elastomeric chains. Braz Dent J 2012;23:394-398.

4 - Behnaz M, Dalaie K, Hosseinpour S, Namvar F, Kazemi L. The effect of toothpastes with bleaching agents on the force decay of elastomeric orthodontic chains. Eur J Dent 2017;11:427-431.

5 - Behnaz M, Namvar F, Sohrabi S, Parishanian M. Effect of bleaching mouthwash on force decay of orthodontic elastomeric chains. J Contemp Dent Pract 2018;19:221-225.

6 - Dittmer MP, Demling AP, Borchers L, Stiesch M, Kohorst P, Schwestka-Polly R. The influence of simulated aging on the mechanical properties of orthodontic elastomeric chains without an intermodular link. J Orofac Orthop 2012;73:289-297.

7 - Halimi A, Azeroual MF, Doukkali A, El Mabrouk K, Zaoui F. Elastomeric chain force decay in artificial saliva: an in vitro study. Int Orthod 2013;11:60-70.

8 - Kassir CA, Daou M, Abboud M. Comparison of the force decay over time of four different brands of elastomeric chains (elongated to $25 \mathrm{~mm}$ grey/transparent and closed/open): An in-vitro study. Int Orthod 2020;18:538-545.

9 - Larrabee TM, Liu SS, Torres-Gorena A, Soto-Rojas A, Eckert GJ, Stewart KT. The effects of varying alcohol concentrations commonly found in mouth rinses on the force decay of elastomeric chain. Angle Orthod 2012;82:894-899.

10 - Menon VV, Madhavan S, Chacko T, Gopalakrishnan S, Jaco J, Parayancode A. Comparative assessment of force decay of the elastomeric chain with the use of various mouth rinses in simulated oral environment: an in vitro study. J Pharm Bioallied Sci 2019;11(Suppl 2):S269-S273.

11 - Pires BU, Souza RE, Filho MV, Degan VV, Santos JCB, Tubel, CAM. Force degradation of different elastomeric chains and nickel titanium closed springs. Braz J Oral Sci 2011;10:167-170.

12 - Pithon MM, Rodrigues AC, Sousa EL, Santos LP, Soares NS. Do mouthwashes with and without bleaching agents degrade the force of elastomeric chains? Angle Orthod 2013;83:712-717.

13 - Paige SZ, Tran AM, English JD, Powers JM. The effect of temperature on latex and non-latex orthodontic elastics. Tex Dent J 2008;125:244-249.

14 - Lacerda Dos Santos R, Pithon MM, Romanos MT. The influence of pH levels on mechanical and biological properties of nonlatex and latex elastics. Angle Orthod 2012;82:709-714.

15 - Ahmed I, Saif-ul-Haque, Nazir R. Carious lesions in patients undergoing orthodontic treatment. J Pak Med Assoc 2012;61:1176-1179.

16 - Ousehal L, Lazrak L, Es-Said R, Hamdoune H, Elquars F, Khadija A. Evaluation of dental plaque control in patients wearing fixed orthodontic appliances: a clinical study. Int Orthod 2011;9:140155.

17 - Kovatch JS, Lautenschlager EP, Apfel DA, Keller JC. Load-extension-time behavior of orthodontic Alastiks. J Dent Res 1976;55:783-786.

18 - Garcia-Godoy F, Garcia-Godoy A, Garcia-Godoy C. Effect of a desensitizing paste containing $8 \%$ arginine and calcium carbonate on the surfasse roughness of dental materials and human dental enamel. Am J Dent 2009;22:21A-24A.

19 - Nattrass C, Ireland AJ, Sherriff M. The effect of environmental factors on elastomeric chain and nickel titanium coil springs. Eur J Orthod 1998;20:169-176.

20 - Ash JL, Nikolai RJ. Relaxation of orthodontic elastomeric chains and modules in vitro and in vivo. J Dent Res 1978;57:685-690.

21 - Kersey ML, Glover KE, Heo G, Raboud D, Major PW. A comparison of dynamic and static testing of latex and nonlatex orthodontic elastics. Angle Orthod 2003;73:181-186.

22 - Baty DL, Storie DJ, von Fraunhofer JA. Synthetic elastomeric chains: a literature review. Am J Orthod Dentofacial Orthop 1994;105:536-542. 
23 - Ferriter JP, Meyers CE Jr, Lorton L. The effect of hydrogen ion concentration on the forcedegradation rate of orthodontic polyurethane chain elastics. Am J Orthod Dentofacial Orthop 1990;98:404-410.

24 - Macedo MM, Venezian GC, Neves JG, Furletti VF, Vedovello-Filho M, Correr-Sobrinho L et al. Evaluation of latex and non-latex intermaxillary elastics strength degradation when submitted to the use of chlorhexidine. Orthod Waves 2021;80:65-70.

25 - Samuels RH, Rudge SJ, Mair LH. A clinical study of space closure with nickel-titanium closed coil springs and an elastic module. Am J Orthod Dentofacial Orthop 1998;114:73-79.

Received: $12 / 05 / 2021$

Accepted: 24/09/2021 